\title{
Retratos negros e buracos
}

\author{
Academicismo e modernismo em Santa Catarina ${ }^{1}$ \\ Sandra Makowiecky ${ }^{2}$ e Marina Rieck Borck ${ }^{3}$
}

\begin{abstract}
Participantes do Grupo de Pesquisa (SC): Giorgio Vicenzo Filomeno ${ }^{4}$
Participantes do Grupo de Pesquisa ( $\mathrm{AL}$ ): Ana Lúcia Gil, Kamilla Nunes, Letícia

Weiduschadt, Rachel Reis de Araújo ${ }^{5}$
\end{abstract}

RESUMO: Desde as primeiras manifestações culturais do homem a representação da figura humana é tentativa recorrente. As pinturas rupestres já tratavam desta questão, da busca de uma identidade, de um rosto para aquele ser desconhecido - uma imagem para o próprio homem. Este artigo parte deste começo para tratar de retratos produzidos por artistas modernos latino-americanos - pensando o retrato como noção operatória, e por isso mesmo descolado de discursos como o da regionalidade ou o da biografia como explicação da obra, apesar de respeitar o recorte proposto.

PALAVRAS-CHAVE: academicismo, modernismo, teoria e crítica de arte, arte brasileira, arte latino-americana, história da arte.

O RECORTE: As imagens de que trata este artigo foram escolhidas dentre milhares de pinturas modernas latino-americanas, compreendidas no período que vai do início do século XX até meados de 1950, variável, conforme as peculiaridades de cada país em relação à arte e ao moderno, pesquisadas pelo grupo "Academicismo e modernismo em Artes Plásticas em Santa Catarina”. O procedimento para o recorte do olhar proposto aqui procurou uma inquietação não nova, ao contrário, talvez das mais antigas da história da pintura universal: o rosto e sua ausência quando da representação do homem. Devido à aproximação entre os grupos de pesquisa, um responsável pelo academicismo

\footnotetext{
${ }^{1}$ Academicismo e modernismo em Santa Catarina- UDESC, Centro de Artes

${ }^{2}$ Orientadora, professora do Departamento de Artes Plásticas do Centro de Artes - UDESC.

${ }^{3}$ Acadêmica do Curso de Bacharelado em Artes Plásticas - Ceart/UDESC, bolsista PROBIC, UDESC.

${ }^{4}$ Acadêmico do Curso de Bacharelado em Artes Plásticas - Ceart/UDESC, bolsista PROBIC, UDESC, participante da pesquisa Academicismo e Modernismo em Santa Catarina.

${ }^{5}$ Acadêmicas participantes do projeto Academicismo e Modernismo na América Latina, do mesmo grupo de pesquisa das orientadoras Sandra Makowiecky (coordenadora do projeto SC)e Rosangela Miranda Cherem ( coordenadora do projeto AL). Ana Lúcia Gil, bolsista PROBIC, acadêmica do curso de Artes Plásticas; Kamilla Nunes, bolsista PROBIC, acadêmica do curso de Artes Plásticas; Letícia Weiduschadt, bolsista PROBIC, acadêmica do curso de Artes Plásticas; e Rachel Reis de Araújo, bolsista voluntária e também acadêmica do curso de Artes Plásticas.
} 
e modernismo em Santa Catarina e o outro pelo mesmo recorte temporal na América Latina, e pela participação do procedimento por ambos os grupos - esboçamos a problemática sobre o arsenal imagético e suas possibilidades de abordagem, particularmente no que se refere a questões relacionadas à cronologia e anacronismo, semelhança e dessemelhança, proximidade e distância, superfície e profundidade achamos por bem concentrarmos nas imagens e nos problemas que a seleção feita acarreta para a História da Arte, dentro de todo nosso arsenal imagético, sem nos concentrarmos na questão do território onde foram feitas as imagens, dentro de nosso amplo espectro de interesse. Por isso, vamos nos deter neste artigo em particular em artistas latino-americanos, ao invés dos artistas catarinenses. O que nos interessa é a reflexão possível na leitura de imagens e as possibilidades de estudar a história da arte, no âmbito do grande grupo de pesquisa, do qual participa com alto grau de importância o grupo sobre Academicismo e Modernismo na América Latina.

O PROBLEMA: Pode-se mesmo questionar que pessoas são estas, cujos rostos não se mostram nos quadros onde pousam retratadas. De que modo o rosto serve ao homem que emoções pedem que o rosto seja retirado da cena; quando é retirado da idéia de homem? Este artigo procurará relacionar as imagens latino-americanas selecionadas com questões universais acerca do rosto e do retrato, pensando-o como noção operatória mais que como uma forma de representação tradicional a serviço de discursos que vão para além da própria questão humana. Em última instância, o que se pretende neste artigo é libertar o retrato de sua função tradicional, que visa reconhecer no homem um rosto já recheado de significados. Nestas imagens o rosto não aparece, mesmo quando se mostra. Os olhos são vazios, vazados, quando existem. No percurso da narrativa proposta pelas imagens latinas, seguindo o recorte de imagens proposto, será possível perceber o quanto o ato de esconder o rosto com as mãos talvez seja mais recheado de significados para além do próprio homem do que o rosto e os olhos desenhados - que muitas vezes representam o abismo, na linha de Blanchot e Bataille, dois autores fundamentais para este raciocínio. Das camadas de Didi-Huberman, o presente artigo retira sua noção de retrato, do retrato como ausência, falta, como buraco. O problema, aqui, são os rostos que não se representam, ao contrário, mostram o quanto descoincidentes são consigo mesmos; o problema é o corpo como bloco, como caixa, como espaço. O problema, aqui, é a semelhança - não a semelhança a alguma coisa, positiva, 
mas segundo o raciocínio de Roger Callois, em sua Psicastenia Legendária "simplesmente semelhança"

A MÁSCARA: O rosto não é um assunto novo, sabe-se das antigas representações do homem pelo homem, quando ainda talvez não se soubessem já determinados pelos gestos humanos. Neste tempo remoto, em meio a pinturas de animais e caças feitas em paredes, aquele homem propunha para si uma imagem - um rosto: um rosto não humano, mas daquela caça que confrontavam. O rosto do homem era o pássaro; o da mulher era o corpo, as ancas, os seios. Mas que forma teria o olho que refletia tais absorções?

Ao longo da História da Arte, a representação que o homem faz de si - e o uso que faz de sua própria imagem em função de um dizer qualquer - sempre foi assunto recorrente. Talvez haja questões regionais que diferenciam o uso da figura humana a serviço de uma idéia estruturada e sistematizada, em função de um discurso implicado com um determinado contexto histórico, por exemplo. No entanto, parece precipitado afirmar o uso da figura humana - do rosto - apenas como um veículo político partidário de causas alheias à própria condição humana. Nem sempre ele representa alguma coisa para além do que esconde. Seja na pré-história, nas pinturas das cavernas, onde aparece a figura humana pelas primeiras vezes, seja nas imagens feitas por pintores modernos da América Latina de diversos países, em maior ou em menor grau de comprometimento com questões exteriores, percebe-se a retirada do rosto quando se pretende acessar o máximo da condição humana: a angústia gerada pela falta - de vida, de olhos, de força. Quando o rosto sai da cena é a pergunta. O que aparece quando ele sai. Quando ele é retirado - e quando deve ser retirado?

${ }^{6}$ Callois, p. 63 
Essa superfície nervosa que se chama rosto. Nas pinturas latino-americanas ele é representado de diversas formas e recebe vários significados a partir delas. Os primeiros

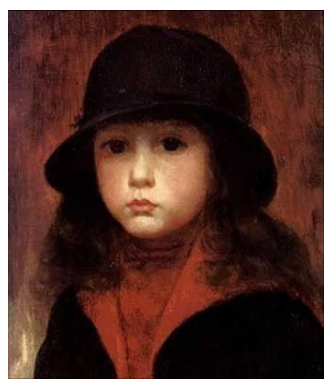

Figura. 1 - Chile. Alfredo Valenzuela Puelma. 'Meu filho Rafael'. S/ dados

exemplos desta série, numa clave impressionista, os rostos sustentam olhos melancólicos, tristes, como o rosto da criança do chileno Alfredo Valenzuela ( Fig. 1). De rosto inerte, parado, os olhos da criança transbordam tristeza, porém uma tristeza contida, já um pouco distanciada do momento máximo do encontro com a dor, como quem apenas narra através do olhar um evento passado. O clima impressionista de Mary Cassatt e James McNeill Whistler aparece muito forte nesses olhos fundos e distantes. Também o clima dado pela influência das grandes pinturas realistas espanhóis sobre o olhar de Alfredo Valenzuela.

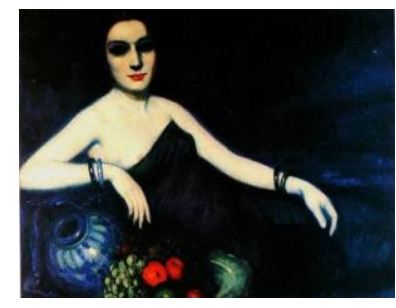

figura. 2 - Chile. Camilo Mori Serrano. 'Mulher de azul'. S/ dados

Também na outra imagem, na 'Mulher de Azul'( Fig. 2), cuja melancolia do corpo fala no lugar dos olhos, os olhos são opacos, buracos. A vaporosidade da carne, inapreensível, é reforçada pelo negrume dos olhos que se voltam para quem a olha, a quem ela se oferece. A moça de Camilo Mori não parece mais que um corpo, um invólucro capaz ao sexo, cujos olhos vazados ausentam-se da oferta: seu rosto sorri fraco, seus olhos ameaçam e não se mostram, ao contrário de seu busto, que se mostra e insinua abrir-se para quem quiser. Há uma espécie de resignação débil no sorriso, neste seio em meio a frutas. Há a resignação da condição de um corpo que não pertence ao 
rosto - e este remete ao corpo; o sorriso é forçado, aparecido de traz do buraco dos olhos, das uvas, e das maçãs. Um quadro cujo estilo dialoga com o que havia de vanguarda na Europa do início do século. Camilo Mori esteve por duas vezes na Europa. Da França trouxe as primeiras insertivas modernas, quando abandonou o realismo popular. Entre as estadas nesses lugares todos, era o Chile quem o abrigava e respondia a suas perguntas.

São todos rostos: mostram-se ao mesmo tempo em que se velam. Ao se velarem, por contrário, sugerem uma série de possibilidades. As imagens que seguem ( Fig. 3, 4 e 5) são de rostos escondidos por mãos expressivas.

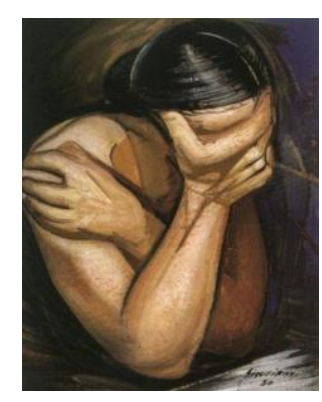

Figura. 3 - México. David Alafaros Siqueiros 'Angústia (mãe do artista)' 94x76 cm

Em três imagens seus pintores trocaram a face pelas mãos, pelos ombros. Nesta série, quem os representou foram os artistas David Alafaros Siqueiros e o equatoriano Eduardo Kingman. O mexicano adotou as causas populares e se engajou na luta em favor da revolução com ideais comunistas e do povo mexicano. Chegou a fazer pintura de cavalete, mas destacou-se pelos murais. Compunha o grupo de muralistas mexicanos, entre Orozco e Rivera. Eduardo Kingman adota a semelhança dos muralistas mexicanos, adota a retórica deles; expressa-se com um desenho grosseiro, fortemente delineado, a linha rica de expressividade. Constrói as figuras com um realismo rigoroso, a serviço do discurso da carne que é capaz de identificar nos corpos que representa em seus quadros.

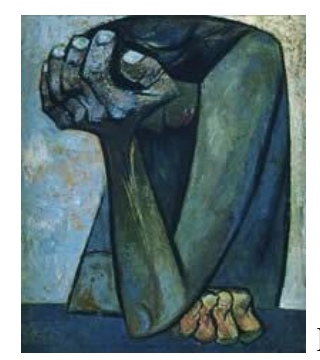

Figura. 4 - Equador. Eduardo Kingman. S/ dados 
Aquilo que estamos habituados a perceber nas feições do rosto, no olhar, é passado neste contexto pela expressão das mãos. Elas escondem os rostos, o acento é transferido do sensível da pessoa através de seu olhar, interno, privado, para as mãos, expostas, destinadas ao trabalho - estas falam sob o viés do drama humano, da dor ostensiva e do sofrimento. São imagens, como foi dito, bastante trabalhadas pelos muralistas, que assumiram a causa do povo e se valeram da arte para construir mensagens em favor da minimização do sofrimento humano - cunho social. Mas percebe-se uma diferença de estilo bastante grande no traço de Kingman e de Siqueiros. Kingman parece ultrapassar

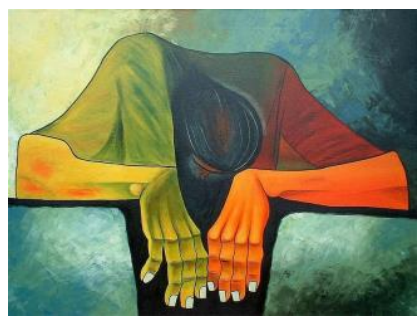

Figura. 5 - Equador. Eduardo Kingman. 'Agobio'. S/ dados

a causa populista, apesar de usar a forma do corpo comumente usada em favor deste discurso. Especialmente este, retratou o cansaço, mesmo que um cansaço social, quando abandona o corpo de suas figuras às mãos e ao chão, à descrença. É como se fossem seus corpos apenas carne e desilusão, tristeza. Para não cair, apóiam-se nas juntas do próprio corpo, apegados à matéria como tábua de salvação. As mãos são apoios da alma. Os ombros se elevam acima da cabeça. O gesto das figuras, na superfície, representa a dor humana e faz referência às questões sociais da latino-américa, ao estilo criado no México, consagrado como latino-americano. No entanto, ressalta-se o cansaço representado pelas costas altas, pois é isto que as imagens tratam. O abandono do corpo a sua própria sorte deixando apenas um bloco de significados formado por carne. Uma carne segura nos ossos, no quanto eles puderem estender-se; o resto é mole, derramado. Tamanho abandono cria limites finos com o do corpo estendido no chão - com o corpo da morte, o corpo do sono. 


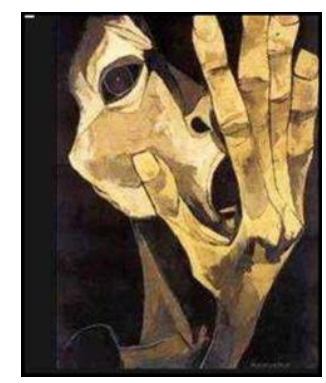

Figura. 6 - Equador. Oswaldo Guayasamin. 'O grito I', 1983. Óleo s. tela, 130 x 90 $\mathrm{cm}$

O horror acompanha certos limites, o grito é alto na história da arte. Guayasamin (fig. 6) mostra o horror em parte, a boca aberta, o buraco do olho, o rosto metade coberto, metade grito. Este pintor equatoriano trata do tema em vários de seus quadros. Ele mostra o rosto do medo, de quem viu o medo - o horror apenas pode ser visto pelos olhos que o viram. Guayasamin retrata o rosto de quem presenciou o inominável, o indizível, que só pode ser registrado se registrado deste rosto que o vivenciou. Sua vida artística foi tradicional, burguesa, recheada de exposições individuais em importantes museus pelo mundo. Gradua-se como Pintor e Escultor na Escola de Belas Artes de Quito; pensar que tal mistura de faturas tenha resultado em tamanha expressão do grito, que é a parte que cabe a este texto. Percebe-se no quadro em questão a dramaticidade cênica, dada pela materialidade, pela densidade escultórica da pintura.

O rosto é fino, a pele é fina, capaz de rasgar-se. É nervosa bem na superfície, treme quando faltam noites dormidas e sobram vidas conturbadas, quando desdobra-se do horror. César Aira fala da impressão de Krause sobre o rosto do amigo Rugendas depois de descrever para o leitor o estado deste rosto atingido por um raio, melhor, Aira fala de impressões sobre um rosto que vivenciou o horror: "Krause estremecia só de pensar como era frágil um rosto. Basta um golpe e já está destruído para sempre, como um vaso de porcelana. Em compensação, um caráter era algo mais durável e uma disposição psicológica parecia eterna." ${ }^{, 7}$ Rugendas escondeu o horror de seu rosto com uma mantilha preta, rendada. Guaysamin escondeu parte do horror com as mãos. Estes rostos ainda representam algo para além de si, mas ainda existe um objeto a que se destina a expressão deste rosto que se esconde.

Em artigo publicado numa revista de cultura, Augusto Contado Borges analisa umas imagens que acompanharam as inquietações de Bataille sobre a condição humana, sobre a dor; fotos de um supliciado chinês - um infrator chinês no início do século cuja

\footnotetext{
${ }^{7}$ Aira, 2006. p. 60
} 
pena foi ser esquartejado em cem pedaços, tendo sua pele retalhada e seu corpo despedaçado, ainda vivo, em praça pública. Ainda em relação à Rugendas, sob efeito do ópio, esta droga tinha sob o supliciado função oposta à morfina usada pelo pintor viajante: "Afinal, o ópio lhe havia sido ministrado para isso: prolongar seu sofrimento a fim de forçá-lo a viver na própria pele seu maior e derradeiro papel." ${ }^{8} \mathrm{O}$ rosto do êxtase é ausente do próprio corpo, abandona seu corpo para suportá-lo, ainda, depois. Nas palavras do artigo:

\begin{abstract}
“(...) vemos porções de seu corpo arrancadas, membros decepados, a pele em carne viva, o sangue escorrendo das chagas multiplicadas por toda a superfície. A despeito de tudo, seu rosto conserva uma expressão bizarra, desafiadora, como se não fizesse parte da cena: um rosto fora de cena, de lugar, de sentido. Na mais contraditória das imagens, a jovem vítima parece não sentir o que sente. A aparência do supliciado numa das fotos é a de um sujeito que não se coaduna com o corpo. No entanto, era justamente esse corpo que ia aos poucos sendo impiedosamente retalhado pelos carrascos imperiais.(BORGES, 2001).
\end{abstract}

Eis o problema. Na medida em que o rosto se ausenta da cena, quando a expressão não coincide com a representação simbólica de expressão adequada a cada experiência de que se possa falar; quando o rosto se depara com o absurdo e não responde mais à consciência, o que se vê? Na medida em que a presença do corpo é mais solicitada, através da dor, do suplício, onde se encontra o ser a quem pertenceria aquele corpo? É possível atribuir o rosto do supliciado ao corpo sob tortura? É puro corpo - e ausência.

Na pré-história a figura humana não tinha um rosto seu que não fosse roubado das aves ou de outros bichos. Usavam máscaras e escondiam seus rostos - atrás das mãos. Quando gravavam a palma da mão nas paredes das cavernas, ainda quando representava o mundo abstratamente, através de risco e pontos repetidamente dispostos em cavernas anteriores à Lascaux. Didi-Huberman sugere um "lugar humano" a partir destes "primeiríssimos traços de humanidade" $\mathrm{em}$ texto que trata do retrato. O homem da caverna estava já ensaiando um rosto seu, apesar de escondê-lo. Segundo o autor, o rosto teve suas primeiras inscrições no mundo quando algum homem ritualizou a ausência, o buraco, deixada pela morte do outro. Ritualizou o outro através de algum gesto: este é o retrato: ritualização do outro ausente. Antes mesmo de representar-se a si enquanto figura distanciada do meio, ainda os primeiros homens usavam características alienígenas a eles para se representarem, a ausência de seu próprio rosto foi preenchida pelo rosto do outro: o pássaro emprestou-se ao homem, que não se sabia distinto dele. A 
cabeça do pássaro substituiu a cabeça do homem, quando para este ainda não havia rosto, apenas buraco, ausência, intuição e dessemelhança. Hoje a cabeça do pássaro acompanha o animal a que se destina por semelhança positiva, não segundo a semelhança defendida por Callois, ou a do homem pré-histórico. Hoje crê-se em uma imagem humana, e pretende-se lugares certos para as coisas. No entanto, este deslocamento de objeto acontecido nas cavernas continua havendo. Hoje acontece sob outra perspectiva, de acordo com nosso tempo, através do suporte e do discurso atuais, porém, cujo significado atribuído pode ser exatamente o mesmo que atribuímos aos deslocamentos pré-históricos. Ou seja, houve um segundo deslocamento, deslocou-se, ao contrário de nossos antepassados, o objeto permanece - a cabeça é a mesma, e novamente restitui-se o buraco - desloca-se o lugar do rosto. Agora vemos a ausência por semelhança, um rosto assemelhando-se ao rosto ausente.

Depois de tanto tempo, ainda na modernidade, os pintores latinos - como outros tantos, a começar por Francis Bacon e seus infinitos ensaios sobre a condição humana e seu retrato - retiram seu rosto da figura. Ausentam os rosto de expressão. Retiram do homem o que o difere de outros animais, devolvendo-lhe seu maior traço distintivo, o

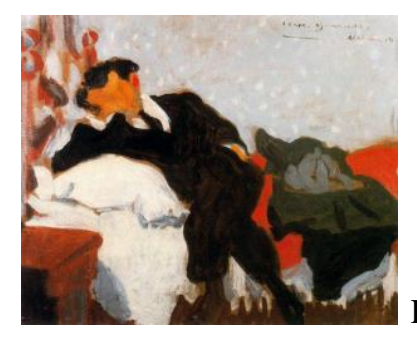

Figura. 7 - Uruguai. Rafael Barradas. 'Estudo', 1914. Óleo s. cartão, 46 x 54 $\mathrm{cm}$

profundo do humano. Rafael Barradas, uruguaio, torna suas figuras desanimadas( Figs. $7,8,9,10)$. Os olhos são buracos resignados, semelhantes a nada, cegos, quase ausentes do corpo e da cena, ainda quando estão esboçados. As figuras perdem o movimento para a paralisia do corpo inerte, estático, parado. O pintor teve uma carreira consistente, de cujo intelectual, convivendo com pensadores ao freqüentar saraus e deixar-se contaminar pelos pensamentos filosóficos e literários. Desenhista, fez cartazes e ilustrações para revistas. 
Figura. 8 - Uruguai. Rafael Barradas. 'Pilar', 1922. Óleo s. tela, 114 x 73

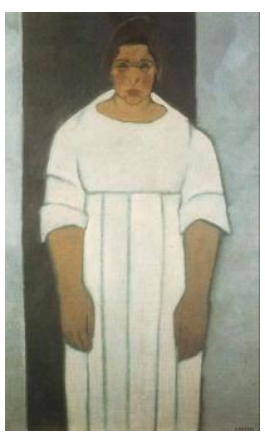

Figura. 9 - Uruguai. Rafael Barradas. 'Pilar', 1922. Óleo s. tela, 114 x 73 cm

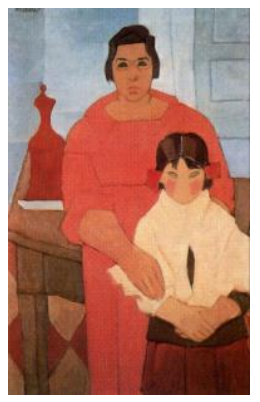

Fig. 10 - Uruguai. Rafael Barradas. 'Pilar e Antoninha', 1922. Óleo s. tela, 114 x 73 cm

Esta última série de imagens representa o corpo visto por Rafael Barradas, o corpo confundido com bloco, coincidente com o vazio de sentido. Os rostos mal esboçam traços reconhecíveis - se há, têm olhos opacos ou inexistentes. Só sombra. As figuras são contidas no corpo e se lançam ao observador através de olhos obliterados, são ocelos; os blocos são mimetizados em corpos - cabeças imitam rostos, buracos imitam olhos e blocos imitam corpos. Pura semelhança sem objeto. Olhos de vidro, olhos apagados, rostos inexistentes e expressão nenhuma de humanidade no corpo. Os retratos são formais e tradicionais, enganando solenemente o vidente desavisado: meio corpo estendido virado para frente. Barradas parece enxergar o mesmo que Callois, a partir de outro lugar. Callois se espanta com a mimetização de uns animais em especial com o meio; Barradas sugere o espanto da coincidência do corpo do homem consigo próprio. Ambos tocam na questão da semelhança - semelhança com nada. Através de um procedimento metonímico, o pintor latino faz uma série de retratos com mesma forma. 
Repete várias vezes o bloco com significação humana - pois nomeia os quadros com nomes próprios, como se fossem os nomes das pessoas retratadas. Figuras que se assemelham aos nomes, sem rostos ou gestos. No entanto, as figuras marcam um lugar: elas estão ali, ocupando um espaço, como ocupa o corpo que dorme, para Blanchot.

A CONCLUSÃO: A questão maior tratada neste artigo, portanto, vem a ser o retrato e seus desdobramentos em imagens modernas da América Latina, confirmada através especialmente das imagens do uruguaio Rafael Barradas, que trouxe em seus quadros a discussão iminente sobre o retrato feita por grandes teóricos, em acordo e concordância direta com questões universais que atravessaram o tempo, chegando aos dias de hoje tratando destas questões tão enigmáticas como o eram em tempos passados. Seu retrato, apesar de intentar mostrar o retrato tradicional, foge a ele. Os olhos incisivos e vazios retratados por Barradas não remetem a outras questões que não sua existência mesma, o seu próprio vazio. Seriam suas imagens, portanto, o retrato como noção operatória, ao invés de simples representação de pessoas.

Abaixo, outro retrato, de Franscisco Goitia ( Fig. 11), como mais uma tentativa de esclarecer e confirmar a tese aqui proposta. Em sua vida, além de passar mais de 5 anos na Europa, ao voltar para o México, aliou-se a um general de guerra, como seu pintor oficial, por isso acompanhando-o e aos seu exército por todas as partes que fossem. Acompanhou muita guerra e muita morte. Goitia mostrou os estragos e sofrimentos que estes também significaram para o povo do México. O 'povo' de Goitia parece desiludido da salvação, estão mais próximos, mais uma vez, do real da condição humana - não é mais o sofrimento cênico anterior à morte. Também retirou-se novamente da "civilização" ao morar em meio a índios ao lado de um antropólogo amigo, onde atuou como mestre e promotor. O quadro 'Tata jesus Cristo', abaixo, é um de seus mais conhecidos, e traz o rosto ausente e o rosto da dor extrema.

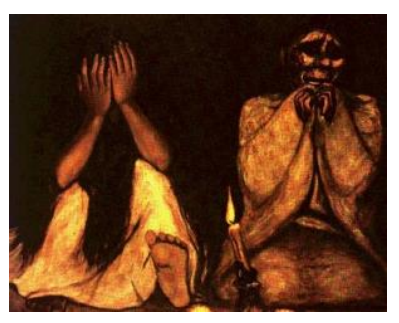

Figura. 11 - México. Francisco Goitia. 'Tata Jesucristo', 1926.

O rosto e sua ausência nos serviram de motivo para pensar questões relacionadas em especial ao anacronismo, através de uma possível reflexão sobre a leitura de 
imagens - e as possibilidades de estudos da história da arte. A série proposta pretendeu libertar o retrato de sua função tradicional e reconhecida, que crê haver nos rostos apenas certas e determinadas interpretações, que não vê no rosto mais que superfície recheada de significados.

\section{REFERÊNCIAS BIBLIOGRÁFICAS}

AIRA, César. Um acontecimento na vida de um pintor viajante. Trad. Paulo Andrade Lemos. Rio de Janeiro: Nova Fronteira, 2006

BATAILLE, Georges. Lascaux: o el nacimiento del arte. Argentina: Alción Editora, 2003.

BRODRICK, A. Houghton. La Pintura prehistórica. Trad. Helena Pereña de Malagón. México: Fondo de Cultura Econômica, 1965.

CAILLOIS, Roger. Mimetismo e psicastenia legendária. Revista Che Voui, ano 1, $\mathrm{n}^{\mathrm{o}}$, Cooperativa Cultural Jacques Lacan, Porto Alegre: 1986.

DIDI-HUBERMAN, Georges, $O$ rosto e a terra. In.: PORTO ARTE, v. 9, n. ${ }^{\circ}$ 16, p. 1 116, maio 1998. Porto Alegre, Porto Arte: instituto de Artes/ UFRGS, 1990.

FREUD, Sigmund. "Lo siniestro" (1919), in Obras Completas Tomo 3, tr. L. LópezBallesteros, Bs.As.: El Ateneo, 2005. pp.2483-2505.

SYLVESTER, David. Entrevistas com Francis Bacon. Trad. Maria Tereza Resende Costa. São Paulo: Cosac Naify, 2007

BORGES, Augusto Contador. Georges Bataille: Imagens do êxtase. Disponível em <http://www.revista.agulha.nom.br/ag9bataille.htm> Acesso em 27 jun.2008.

\section{REFERÊNCIA DAS IMAGENS}

CHILE. ALFREDO VALENZUELA PUELMA (Valparaíso, 1856 - Villejuif, Franca, 1909). 'Meu filho Rafael': Disponível em < http://images.google.com.br/imgres?imgurl=http://www.profesorenlinea.cl/imagenbiogr afias/valenzuelaPuelma000.jpg\&imgrefurl=http://www.profesorenlinea.cl/biografias/Va lenzuelaPuelma.htm \&h=550\&w=375\&sz=98\&hl=pt-

BR\&start $=7 \& u m=1 \&$ tbnid=923oZfBehOJqtM:\&tbnh=133\&tbnw=91\&prev=/images $\%$ 3Fq\%3DALFREDO \%2BVALENZUELA\%2BPUELMA\%2B\%26um\%3D1\%26hl\%3D pt-BR>Acesso em 24 jun.2008.

CHILE. CAMILO MORI SERRANO (Valparaíso, 1896 - Valparaíso, 1973). 'Mulher de azul':Disponível em<

http://www.portaldearte.cl/obras/mujeraz.htm> Acesso em 24 jun.2008. 
MÉXICO. DAVID ALAFARO SIQUEIROS (1896-1972) 'Angústia (mãe do artista)' $94 \times 76 \mathrm{~cm}$ :Disponível em <

http://images.google.com.br/imgres?imgurl=http://www.marxists.org/subject/art/visual arts/painting/exhibits/muralists/angustia.jpg\&imgrefurl=http://melcomcicuta.blogs.sapo. $\mathrm{pt} / 48656 . \mathrm{html} \% 3$ Fmode\%3Dreply \&h=510\&w=400\&sz=51\&hl=pt-

BR\&start=2\&um $=1 \&$ tbnid=v6VCGa4qcQ4jmM:\&tbnh=131\&tbnw $=103 \&$ prev=/image s\%3Fq\%3DDAVID\%2BALFARO\%2BSIQUEIROS\%2B\%2527Ang\%25C3\%25BAsti a\%2527\%26um\%3D1\%26hl\%3Dpt-BR\%26sa\%3DN>. Acessado em 24 jun.2008.

EQUADOR. EDUARDO KINGMAN (Loja, 1913 - Quito, 1997). Disponível em < http://images.google.com.br/imgres?imgurl=http://fe-

mail.gr/media/Image/relationships_child/2007/sex/7/cheaters/eduardo_kingman.jpg\&im grefurl=http://fe-mail.gr/pages/posts/sex/sex1733.php\&h=238\&w=200\&sz=12\&hl=ptBR\&start=9\&um $=1 \&$ tbnid=L3FQJHxxYJlivM:\&tbnh $=109 \&$ tbnw $=92 \&$ prev $=/$ images $\%$ 3Fq\%3Deduardo\%2Bkingman\%26um\%3D1\%26h1\%3Dpt-BR\%26sa\%3DN> Acesso em 24 jun.2008.

EQUADOR. EDUARDO KINGMAN (Loja, 1913 - Quito, 1997) 'Agobio':Disponível em

<http://images.google.com.br/imgres?imgurl=http://www.ecodeal.com/images/Kingman Category.jpg\&imgrefurl=http://www.ecodeal.com/index.php\%3FcPath\%3D23\&h=120 $\& \mathrm{w}=90 \& \mathrm{sz}=16 \& \mathrm{hl}=\mathrm{pt}-$

BR\&start=11\&um=1\&tbnid=P0YRlO_nbtiu7M:\&tbnh=88\&tbnw=66\&prev=/images\% 3Fq\%3Deduardo\%2Bkingman\%26um\%3D1\%26hl\%3Dpt-BR\%26sa\%3DN> Acesso em 24 jun.2008.

EQUADOR. OSWALDO GUAYASAMIN (1919 - 1999) 'O grito I', 1983. Óleo s. tela, 130 x $90 \mathrm{~cm}$. Disponível em <

http://images.google.com.br/imgres?imgurl=http://bp1.blogger.com/a3mGocA8BY8/R yibWyBcinI/AAAAAAAAABE/mL196GYKEwo/s400/guayasamin.jpeg\&imgrefurl=htt p://bahgassite.blogspot.com $/ \& \mathrm{~h}=400 \& \mathrm{w}=267 \& \mathrm{sz}=29 \& \mathrm{hl}=\mathrm{pt}-$

BR\&start $=14 \& u m=1 \&$ tbnid $=$ Sn-

0I2VH3xVFDM:\&tbnh=124\&tbnw=83\&prev=/images $\% 3 \mathrm{Fq} \% 3$ Doswaldo $\% 2 \mathrm{Bguayasa}$ min\%2Bo\%2Bgrito\%2BI\%26um\%3D1\%26hl\%3Dpt-BR>. Acesso em 24 jun.2008.

URUGUAI. RAFAEL BARRADAS (montevidéo, 1890 - 1929, Idem) 'estudo', 1914.

Óleo s. cartão, 46 x $54 \mathrm{~cm}$. Disponível <

http://pintura.aut.org/BU04?Autnum=14.199>. Acesso em 24 jun.2008.

URUGUAI. RAFAEL BARRADAS (Montevidéo, 1890 - 1929, idem) 'Pilar', 1922.

Óleo s. tela, 114 x 73 . Disponível em <

cmhttp://pintura.aut.org/BU04?Autnum=14199\&Empnum=0\&Inicio=76>. Acesso em 24 jun.2008.

URUGUAI. RAFAEL BARRADAS (Montevidéo, 1890 - 1929, idem) 'Pilar', 1922.

Óleo s. tela, 114 x $73 \mathrm{~cm}$. Disponível em <

http://pintura.aut.org/BU04?Autnum=14199\&Empnum=0\&Inicio=31> Acesso em 24

jun.2008. 
URUGUAI. RAFAEL BARRADAS (Montevidéo, 1890 - 1929, idem) 'Pilar e Antoninha', 1922. Óleo s. tela, 114 x $73 \mathrm{~cm}$. Disponível em < http://pintura.aut.org/BU04?Autnum=14199\&Empnum=0\&Inicio=31>. Acesso em 24 jun.2008.

MÉXICO. FRANSCISCO GOITIA (1882 - 1980) 'Tata Jesucristo”, 1926.Disponível em

$<$ http://images.google.com.br/imgres?imgurl=http://upload.wikimedia.org/wikipedia/co mmons/thumb/3/30/Goitia_9.jpg/759px-

Goitia_9.jpg\&imgrefurl=http://commons.wikimedia.org/wiki/Image:Goitia_9.jpg\&h=6 $00 \& \mathrm{w}=759 \& \mathrm{sz}=75 \& \mathrm{hl}=\mathrm{pt}-$

BR\&start=2\&um=1\&tbnid=8uxanvSmFAdJ0M:\&tbnh=112\&tbnw=142\&prev=/images $\% 3 \mathrm{Fq} \% 3 \mathrm{Dfrancisco} \% 2 \mathrm{Bgoitia} \% 26 \mathrm{um} \% 3 \mathrm{D} 1 \% 26 \mathrm{hl} \% 3 \mathrm{Dpt}-\mathrm{BR}>$ Acesso em 25 jun.2008. 